\title{
Vibration Correlation Dynamics of Cam Follower Systems and Vehicles- Review
}

\author{
Nilesh Ahirrao ${ }^{1}$, Dr.Santosh Bhosle ${ }^{2}$ \\ ${ }^{1}$ Maharashtra Institute of Technology, Aurangabad, nileshahirrao15@gmail.com \\ ${ }^{2}$ Maharashtra Institute of Technology, Aurangabad
}

\begin{abstract}
To reduce the vehicle vibrations is always a major concern in designing a vehicle. The vibrations occur are of two types, torsional and longitudinal vibrations. A vehicle model is utilized for analyzing and measurement of vibrations in it at the time of jump. Vibration values measured on vehicle model are compared with the vibration values in cam-follower systems. If, cam and follower remains in contact, it represents single degree of freedom system. It becomes a two degree of freedom system as soon as the cam and follower separates. This phenomenon of jump creates two new natural frequencies in a system. A force-closed cam-follower was used for the investigation. The system is operated on the cusp of incipient separation. Jump is a situation where the cam and follower physically separate. When they come back together the impact introduces large forces and thus large stresses, which can cause both vibrations. This paper suggests the significance of vibration measurement with experimental modeling and correlation with cam dynamics in vehicle models. The experimentation with results is discussed in this paper.
\end{abstract}

Keywords- cams; follower; jump; vibrations; vehicles

\section{INTRODUCTION}

The vibrating system should possesses high stiffness and high damping in the low frequency range and of low stiffness and low damping in the high-frequency range. Degrees of freedom are critical in a vibratory system. Cam-Follower systems are subjected to single degree of freedom system as far as they are in contact with each other [1]. Engines and vehicles are always subjected to vibrations. Free vibrations occur in engines and vehicles. It is very significant to determine the natural frequencies in such systems. Cam wear in engines are critical regarding vibrations and their performance [2]. Vibration control and damping goes hand in hand in all the vibratory systems. Coulomb damping in the system accounts for surface-to-surface dissipation during oscillation [3]. When we model structural vibrations within fluids, we usually include nonlinear quadratic damping to account for dissipation due to momentum transfer in the fluid [4]. We can also model structural or hysteretic (material) damping in problems with harmonic inputs by using a complex stiffness parameter. Structural damping occurs as material layers slide over one another during vibration. Vehicle vibrations are difficult to analyze and to predict at the time of designing a vehicle [5]. Damping is one of the most difficult phenomena to model in vibrating systems. Mass and stiffness can both be approximated rather accurately using finite element models. Follower vibrations and contact disruptions are important to analyze and to model [6]. In vibratory systems like cam-follower and vehicleroads, the jump and damping estimates are notoriously inaccurate [7]. The idealized static Coulomb friction force is equal to the product of the static friction coefficient between two surfaces, and the normal force between the surfaces [8]. When the follower contact force becomes zero, the cam and follower gets separated. That kind of separation happens with large negative accelerations [9]. In the case of insufficient spring force, the follower will always have the tendency to jump from the cam surface [10]. Very high value of spring force and preload must be applied to the cam follower system so that they remain in contact throughout the motion [11].This large spring force also has the ability to cause problems in a cam follower system. If the spring force is too large, this will increase the contact force, which will induce higher stresses, possibly leading to early surface failure of the parts.

The determination of jump in all systems like camfollower and vehicle-roads requires an effort in detecting the jump and roll overs experimentally and analytically. The conventional cam follower system can be modeled as a single-degree-of-freedom model. At the time of jump, inertia force is larger than the spring force [12]. 


\section{International Journal of Research in Advent Technology, Vol.7, No.4, April 2019 \\ E-ISSN: 2321-9637 \\ Available online at www.ijrat.org}

\section{VIBRATION MEASUREMENT IN DYNAMIC SYSTEMS}

The data from a vibration transducer mounted on a test structure is obtained in time domain. The vibration signal in time domain is useful for finding the overall vibration level in a system or structure. The overall vibration levels will not exactly show the nature of defect that is created in the system. The frequency that is responsible for a particular defect is to be identified rather than the overall vibration level. For this purpose, the vibration signals in time domain are required to get converted into frequency domain. Vibration based condition monitoring is the process in which the mechanical components are periodically checked. Fast Fourier Transforms and the vibration analyzers (FFT Analyzers) are useful in vibration measurement and condition monitoring. Thus, if the absolute or overall vibration level is standardized then it makes vibration based condition monitoring program simple and effective than any other technique. Hence the objective of the present study is to give an indication that, overall or absolute vibration level of a model is important for vibration analysis. Indian road conditions causes causalities due to sudden breakages of vehicle components on some irregularities on roads. Also the performance of vehicle on speed breakers related to vibrations and comfort are very critical to study. This paper correlates the vibration levels in cam follower system with vehicle vibrations. An accelerometer is mounted on chassis frame at the time of jump and the readings are captured for vibration signals and then analyzed in frequency domain for further purpose.

\section{EXPERIMENTAL SETUP -CAM \& FOLLOWER}

Experimental setup for cam-follower system consist of, an eccentric cam and a roller follower. Cam is driven by an electric motor. During the motion at any time, if the contact force becomes zero, then the follower will lose contact with the cam and move independently till the contact is established. Jump-off speed depends on cam profile, type of follower, spring stiffness and preload. Follower mass also plays significant role in jump. Speed of the motor is varied for sets of readings to show the vibration levels at these speeds. Vibrations gets induced due to following usual reasons-

(a) Vibrations due to the shape of the follower

(b) Vibrations due to separation of the cam and the follower. In positive drive cams with backslash, impact of the roller on the cam is produced, and is called cross over shock. With the spring loaded follower it is due to the jump condition, which is significantly affected by spring stiffness.

(c) Vibrations due to surface irregularities, of which they are of many kinds.

(d) Vibrations due to frequency of application of the external loads.

(e) Miscellaneous sources like cam unbalance, production defects, looseness etc.

\subsection{Causes of vibrations in vehicles}

(a) Roughness of road;

(b) Tire imbalance;

(c) Non-uniform tires;

(d) bent wheels;

(e) Driveline and engine.

To reduce the vibrations in the cam follower systems and vehicles, it is very important to sort the most usual reason of vibrations. Many studies shows that the jump on the cam surface and vehicle jumps on roads are major sources of vibrations in such systems.

\section{EXPERIMENTAL SETUP FOR A VEHICLE MODEL}

A vehicle model is built and placed on a travelling belt whose speed can be adjusted by electric motor. The speed is so adjusted that the jump will occur and wheels will be separated from the belt when irregularities hit the tires. At this time the vibrations are measured by FFT analyzer, by keeping accelerometer on chassis frame. Irregularities on the belt, like speed breakers on roads, are attached to belt at certain locations. Different belt speeds are achieved by controlling the motor speed with rheostat.

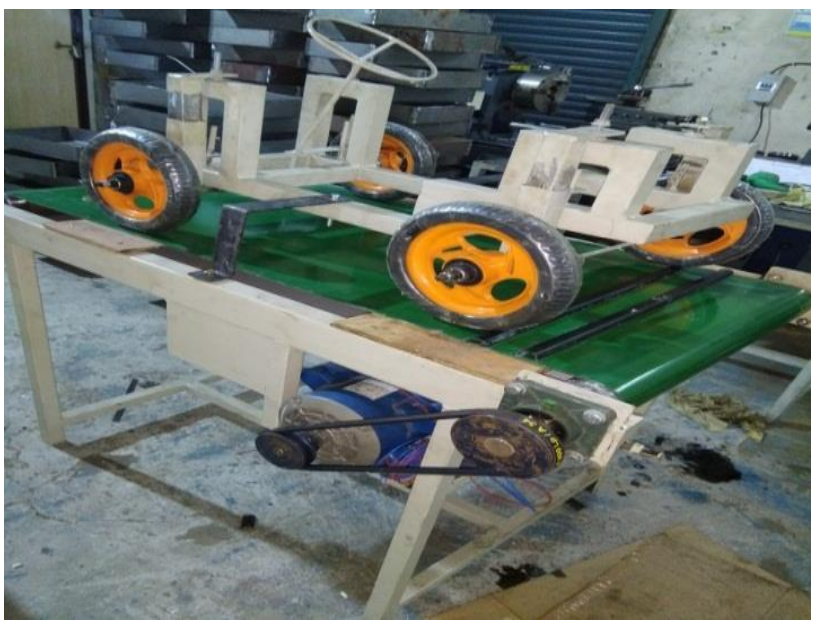

Fig1: A vehicle model on test bench 


\section{Available online at $w w w . i j r a t . o r g$}

\section{VIBRATION RESULTS \& DISCUSSION}

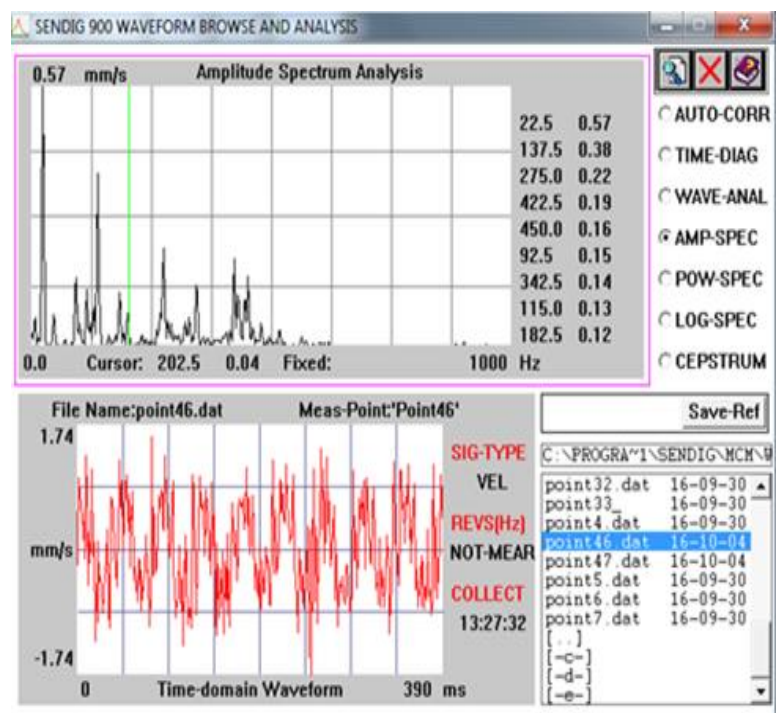

Fig 2: Vibration for cam-follower at the speed of 400 rpm of motor

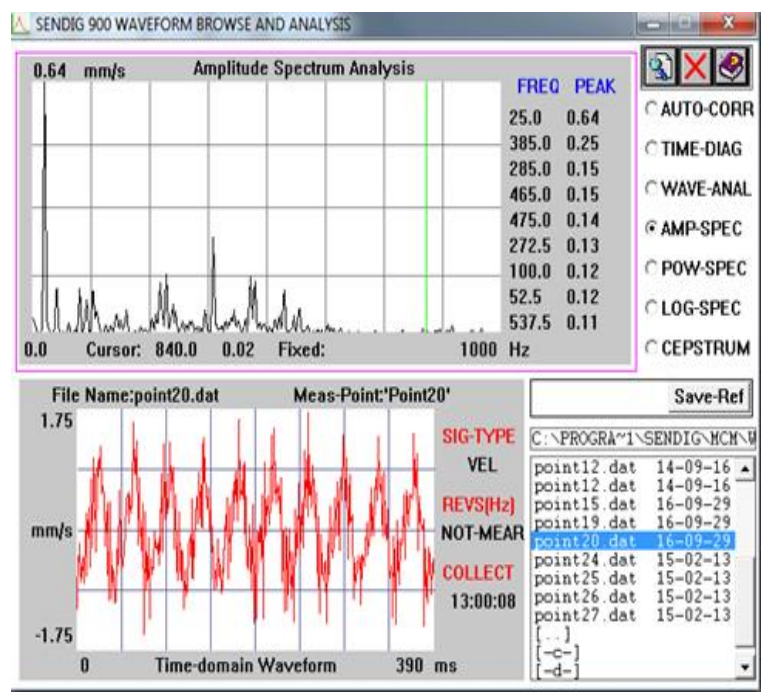

Fig 3: Vibration for cam-follower at the speed of $1000 \mathrm{rpm}$ of motor

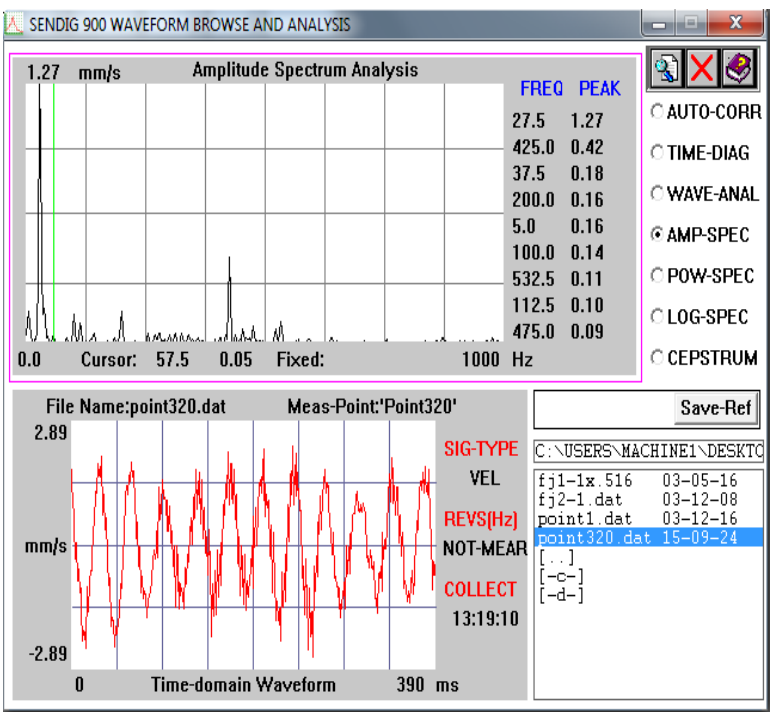

Fig 4: Vibration for vehicle model at the speed of $400 \mathrm{rpm}$ of motor

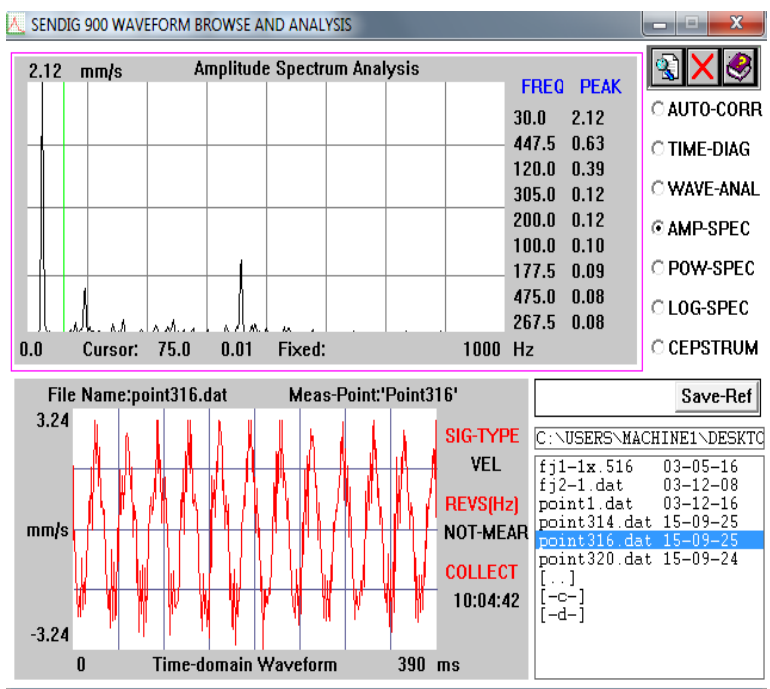

Fig.5: Vibration for vehicle model at the speed of $1000 \mathrm{rpm}$ of motor

\subsection{Discussion}

The values for vibration in cam follower system at the time of jump are ranging from $0.57 \mathrm{~mm} / \mathrm{s}$ to 0.64 $\mathrm{mm} / \mathrm{s}$, for the speed variation of $400 \mathrm{rpm}$ to $1000 \mathrm{rpm}$ of motor. The values are in the safe range of operation, but the peak value is appearing in the low frequency range.

In case of vehicle model the values of vibration values are from $1.27 \mathrm{~mm} / \mathrm{s}$ to $2.12 \mathrm{~mm} / \mathrm{s}$, for the speed range of $400 \mathrm{rpm}$ to $1000 \mathrm{rpm}$ of motor. The peak value in case of vehicle model also appears in low frequency zone at the time of jump. 


\section{International Journal of Research in Advent Technology, Vol.7, No.4, April 2019 E-ISSN: 2321-9637 Available online at www.ijrat.org}

\section{CONCLUSION}

Vibration measurement at the time of jump for camfollower and vehicle models shows that the system behaves like a two degree of freedom system. This is seen from the spectrum significantly, as two prominent peaks are seen in both the cases. Also it is seen that vibrations are very troubling in low frequency ranges. The amplitudes are the major concerns in vehicles at low frequencies. Camfollowers also show the same pattern. This

\section{REFERENCES}

[1] T.K.Naskar and S. Acharyya, Measuring cam follower performance, Mechanism and Machine Theory 45 (2010) 678-691.

[2]Nagaraj Nayaka, P.A Lakshmi Narayananb, Predictions of cam follower wear in diesel engines, Wear, 260 (2006) 181-192.

[3]Takeshi Mizuno and Kenji Araki, Application of Active vibration control techniques to mass measurement, Proceedings of the 1998 IEEE ,International Conference on Control Applications Trieste, Italy 1-4 September 1998,609-613.

[4]Tobias Kloiber, Guido Koch and Boris Lohmann, Modified optimal control of a nonlinear active suspension system, 49th IEEE Conference on Decision and Control December 15-17, 2010, Hilton Atlanta Hotel, Atlanta, GA, USA. 55725577.

[5]Walter V. Wedig, New resonances \& velocity jumps in nonlinear road-vehicle dynamics , Elseiver, Procedia IUTAM Symposium Analytical Methods in Nonlinear Dynamics, 19 (2016), pp.209-218.

[6] Gianluca Gatti, Domenico Mundo, On the direct control of follower vibrations in cam-follower mechanisms, Mechanism and Machine Theory, 45 (2010) 23-35, 2009. correlation is helpful in modeling a vehicle system as like a cam and follower system.

Our concerns therefore should be towards speed enhancement with safety also, which will be possible with selecting proper stiffness and rigidity to the system. Frequency values from spectrum will help in this task. This paper thus shows that, to measure the vibrations for enhancing comfort and safety especially in low frequency range is the area of concern in model development of vehicles.

[7]Wen-Hsaing Hsieh, An experimental study on cam controlled planetary gear trains, Mechanism and Machine Theory, 42(2007)513-525.

[8]Forrest W. Flocker, Addressing cam wear and follower jump in single-dwell cam-follower systems with an adjustable modified trapezoidal acceleration cam profile, Journal of Engineering for Gas Turbines and Power Copyright (C) 2009 by ASME, MAY 2009, Vol. 131 / 032804-1.

[9] Sriram Sundar, Jason T. Dreyer, Rajendra Singh, Estimation of impact damping parameters for a cam-follower system based on measurements and analytical model, Elsevier, Mechanical systems and Signal processing, 81(2016), pp. 294-307.

[10] Livija Cveticanin, Stability of motion of the Cam-follower system, Mechanism and Machine Theory, 42(2007), pp 1238-1250.

[11] B. Demeulenaere, J. De Schutter, Synthesis of inertially compensated variable-speed cams, Journal of Mechanical Design, ASME, September 2003, Vol. 125, p. 593.

[12] Nigam Chandra Parida, Soumyendu Raha, and Anand Ramani, Rollover-preventive force synthesis at active suspensions in a vehicle performing a severe maneuver with wheels lifted off, IEEE Transaction on intelligent Transportation Systems, (2014), pp. 2583-2594. 